\title{
Uncertain Type of Multiple-Attribute Electronic Commerce Investment Decision Model Based on the Close Degree of the Scheme and Its Applications
}

\author{
Fengna Ge*, Xinxin Ding \\ Research Institute of Management Science and Engineering, Henan University, Kaifeng, China \\ Email: "gena2002@163.com \\ Received 6 May 2016; accepted 19 June 2016; published 22 June 2016 \\ Copyright @ 2016 by authors and Scientific Research Publishing Inc. \\ This work is licensed under the Creative Commons Attribution International License (CC BY). \\ http://creativecommons.org/licenses/by/4.0/

(c) (i) Open Access

\begin{abstract}
To deal with the problem of uncertain type of multiple-attribute electronic commerce investment decision whose attribute weights can't be fully known, a index which measures the decisionmaking plan-close degree was Introduced, and a decision-making model based on the scheme close degree was established. The article analyses the application of the model used in investment decisions.
\end{abstract}

Keywords

Multiple-Attribute Decisions, Scheme Close Degree, Decisions

\section{Introduction}

In essence, after determining the comprehensive attribute values of each scheme, multiple-attribute decision making ranks and optimizes the schemes according to their comprehensive attribute values. At presents, the decision making theory and method about the multi-attribute decisions whose attribute weights information is completely known is complete. But in order to deal with the problem of electronic commerce investment decision, decisions made by managers according to their experiences are too subjective, because the weights of factors in the decision making process are difficult to be determined accurately due to the complexity of the economic system and the fluidity of the market situation [1]. The article solves the uncertain type of multiple attribute decision making problems part of whose attribute weights information is completely unknown. In the first "Corresponding author. 
place, a key indicator-scheme close degree was introduced, and then, a decision making model based on the scheme close degree was given which was one of methods to solve the problem.

\section{Basic Theory}

Hypotheses: $X=\left\{x_{1}, x_{2}, \cdots, x_{n}\right\}$ is the scheme aggregate of the decision making problem; $U=\left\{u_{1}, u_{2}, \cdots, u_{m}\right\}$ is the attribute aggregate; $\omega=\left\{\omega_{1}, \omega_{2}, \cdots, \omega_{m}\right\}$ is the weight vector of the attribute; $\omega_{i} \geq 0, \sum_{i=1}^{m} \omega_{i}=1 . H$ is the attribute weight vector according to the known weight information, $\omega=\left\{\omega_{1}, \omega_{2}, \cdots, \omega_{m}\right\} \in H$ [2]. Especially, if $\mathrm{H}$ is null set, attribute weight is completely unknown. Scheme $x_{j} \in X$, attribute $\mathrm{i}$ is measured, and attribute value $a_{i j}$ of $x_{j}$ is got, so decision matrix $A=\left(a_{i j}\right) m \times n$ is made up. Common attribute types are benefit-type, cost-type, fixed-type, interval-type and deviation-type. To eliminate the influence of different physical dimensions to investment decisions, standardize the decision matrix $A=\left(a_{i j}\right) m \times n$ and get $R=\left(r_{i j}\right) m \times n$. The relation of comprehensive attribute value and weight of Scheme $x_{j}$ is

$$
z_{j}(\omega)=0, \sum_{i=1}^{m} r_{i j} \omega_{i}
$$

$\omega_{i}$ is the weight of attribute $u_{i}$.

When weight $\omega_{i}$ is certain, the strengths and weaknesses of each scheme can be known by their comprehensive attribute value. When $\omega_{i}$ is unknown, comprehensively attribute value cannot be got by equation (1) [3]. The situation when attribute weight cannot be completely known will be discussed.

In certain $\omega=\left\{\omega_{1}, \omega_{2}, \cdots, \omega_{m}\right\} \in H$, comprehensive attribute values $z_{j}(\omega)$ are expected to be big. The problem of multi-target decision is thought about.

(MOP) Target function: $\max z(\omega)=\left(z_{1}(\omega), z_{2}(\omega), \cdots, z_{n}(\omega)\right)$

Restraint: $\omega=\left\{\omega_{1}, \omega_{2}, \cdots, \omega_{m}\right\} \in H$

If $\omega=\left\{\omega_{1}, \omega_{2}, \cdots, \omega_{m}\right\}$, this is the optimal solution to the following single-target optimized model:

(SOP1) Target function: $\max z_{j}(\omega)$

Restraint: $\omega=\left\{\omega_{1}, \omega_{2}, \cdots, \omega_{m}\right\} \in H$

$\bar{z}_{j}=\sum_{i=1}^{m} r_{i j} \omega_{i}$ is the comprehensive attribute ideal value of scheme $x_{j}$

$\underline{Z}_{j}=\sum_{i=1}^{m} r_{i j} \omega_{i}$ is the minus comprehensive attribute ideal value of scheme $x_{j}$

If $\omega=\left\{\omega_{1}, \omega_{2}, \cdots, \omega_{m}\right\}$ is the optimal solution to the following single-target optimized model:

(SOP2) Target function: $\min z_{j}(\omega)$

Restraint: $\omega=\left\{\omega_{1}, \omega_{2}, \cdots, \omega_{m}\right\} \in H$

$\bar{Z}=\left(\bar{z}_{1}, \bar{z}_{2}, \bar{z}_{3}, \cdots, \bar{z}_{n}\right)$ and $\underline{Z}=\left(\underline{z}_{1}, \underline{z}_{2}, \underline{z}_{3}, \cdots, \underline{z}_{n}\right)$ are the ideal point and minus ideal point of multi-objective decision problem (MOP) respectively.

The included angle cosine of Scheme comprehensive attribute value vector $z(\omega)=\left(z_{1}(\omega), z_{2}(\omega), \cdots, z_{n}(\omega)\right)$ and ideal point $\bar{z}=\left(\bar{z}_{1}, \bar{z}_{2}, \bar{z}_{3}, \cdots, \bar{z}_{n}\right)$ is:

$$
\cos \alpha=\frac{\sum_{j=1}^{n} \bar{z}_{j} z_{j}(\omega)}{\sqrt{\sum_{j=1}^{n}\left(z_{j}(\omega)\right)^{2}} \sqrt{\sum_{j=1}^{n}\left(\bar{z}_{j}\right)^{2}}}
$$

The included angle cosine of Scheme comprehensive attribute value vector $z(\omega)=\left(z_{1}(\omega), z_{2}(\omega), \cdots, z_{n}(\omega)\right)$ and minus ideal point $\underline{z}=\left(\underline{z}_{1}, \underline{z}_{2}, \underline{z}_{3}, \cdots, \underline{z}_{n}\right)$ :

$$
\cos \beta=\frac{\sum_{j=1}^{n} \underline{z}_{j} z_{j}(\omega)}{\sqrt{\sum_{j=1}^{n}\left(z_{j}(\omega)\right)^{2}} \sqrt{\sum_{j=1}^{n}\left(\underline{z}_{j}\right)^{2}}}
$$


To consider the comprehensive attribute value of each scheme as one unit, scheme close degree is used. Scheme close degree function is:

$$
\begin{aligned}
s(\omega) & =\frac{\cos \alpha}{\cos \alpha+\cos \beta}=\frac{a f(\omega)}{a f(\omega)+b g(\omega)} \\
a & =\sqrt{\sum_{j=1}^{n}\left(\underline{z}_{j}\right)^{2}}, b=\sqrt{\sum_{j=1}^{n}\left(\bar{z}_{j}\right)^{2}} \\
f(\omega) & =\sum_{j=1}^{n} \bar{z}_{j} z_{j}(\omega), g(\omega)=\sum_{j=1}^{n} \underline{z}_{j} z_{j}(\omega)
\end{aligned}
$$

For random $\omega=\left\{\omega_{1}, \omega_{2}, \cdots, \omega_{m}\right\} \in H$, the scheme comprehensive attribute value vector as $s(\omega)$ gets larger, otherwise, the scheme comprehensive attribute value vector will be more similar to minus ideal points when schemes are far away from their optimal condition [4]. So we can consider scheme close degree as a reasonal indicator to measure decision schemes. We maximise this indicator and establish the following single-objective optimised model:

(SOP3) Target function: $\max s(\omega)$

Restraint: $\omega=\left\{\omega_{1}, \omega_{2}, \cdots, \omega_{m}\right\} \in H$, (H is already known)

The optimal attribute weight vector $\omega^{*}$ can be gotten, and then the corresponding scheme comprehensive attribute value vector $z\left(\omega^{*}\right)$ can also be gotten. Schemes are ranked and sorted by their comprehensive attribute value.

According to the above-mentioned theory, an uncertain type multi-objective decision method based on scheme close degree is given. The following are specific

Steps:

1) Decision matrix $A=\left(a_{i j}\right) m \times n$ based on investment decision problem is fomed;

2) Regulate $A=\left(a_{i j}\right) m \times n$ to be $R=\left(r_{i j}\right) m \times n$;

3) Use model (SOP1) and (SOP2) to get ideal point $\bar{z}=\left(\bar{z}_{1}, \bar{z}_{2}, \bar{z}_{3}, \cdots, \bar{z}_{n}\right)$ and minus ideal point $\underline{z}=\left(\underline{z}_{1}, \underline{z}_{2}, \underline{z}_{3}, \cdots, \underline{z}_{n}\right)$;

4) Use equation (2) to calculate a, b;

5) Solve single-objective decision model (SOP3) and get optimal solution $\omega^{*}$, close degree $z\left(\omega^{*}\right)$ and relevant scheme comprehensive attribute value vector $z\left(\omega^{*}\right)=\left(z_{1}\left(\omega^{*}\right), z_{2}\left(\omega^{*}\right), \cdots, z_{n}\left(\omega^{*}\right)\right)$;

6) Rank and sort schemes by their comprehensive attribute value.

\section{Application Exemples}

There are four e-commerce investment schemes $x_{1}, x_{2}, x_{3}, x_{4}$ to be measured. Attributes are company strategy $u_{1}$, market scale $u_{2}$, risk $u_{3}$, capital $u_{4}$, strengths of rivals $u_{5}$ and scope $u_{6}$ [5]. Attribute values of each schemes are shown in Table 1.

Table 1. Attributes value of each scheme.

\begin{tabular}{ccccc}
\hline Attributes scheme & 1 & 2 & 3 & 4 \\
\hline Meet company's & & & & \\
strategies & 0.55 & 0.43 & 0.54 & 0.40 \\
Market scale & 0.47 & 0.57 & 0.43 & 0.52 \\
Risk scale & 0.48 & 0.50 & 0.42 & 0.39 \\
Capital & 0.37 & 0.27 & 0.14 & 0.19 \\
Rivals strengths & 0.17 & 0.35 & 0.19 & 0.20 \\
Developing & & & & \\
prospect & 0.42 & 0.49 & 0.18 & 0.30 \\
\hline
\end{tabular}


$u_{3}$ and $u_{5}$ are cost-type attributes; $u_{1}, u_{2}, u_{4}$ and $u_{6}$ are benefit-type attributes. The weight $\omega_{i}$ of attribute $u_{i}$ is unknown. Certain weight information is:

$$
\begin{aligned}
& H=\left\{\omega=\left(\omega_{1}, \omega_{2}, \omega_{3}, \omega_{4}, \omega_{5}, \omega_{6}\right) \mid 0.2 \leq \omega_{1} \leq 0.4,0.1 \leq \omega_{2} \leq 0.35,\right. \\
& \left.0.1 \leq \omega_{3} \leq 0.3,0.15 \leq \omega_{4} \leq 0.4,0.15 \leq \omega_{5} \leq 0.4,0.05 \leq \omega_{6} \leq 0.15\right\}
\end{aligned}
$$

Pick over schemes.

Specific Steps are:

1) Form decision matrix using figures in Table 1 ,

$$
A=\left(a_{i j}\right) 4 \times 6=\left[\begin{array}{cccc}
0.55 & 0.43 & 0.54 & 0.40 \\
0.47 & 0.57 & 0.43 & 0.52 \\
0.48 & 0.50 & 0.42 & 0.39 \\
0.37 & 0.27 & 0.14 & 0.19 \\
0.17 & 0.35 & 0.19 & 0.20 \\
0.42 & 0.49 & 0.18 & 0.30
\end{array}\right]
$$

2) Use the following formula to regulate matrix $A$,

$$
r_{i j}=\frac{a_{i j}}{\max _{j} a_{i j}}, j \in N, i \in T_{1}, r_{i j}=\frac{\max _{j} a_{i j}}{a_{i j}}, j \in N, i \in T_{2}
$$

$T_{1}, T_{2}$ are sets of benefit-type and cost-type respectively. Standardization matrix is gotten:

$$
R=\left(r_{i j}\right) 4 \times 6=\left[\begin{array}{llll}
1.000 & 0.782 & 0.982 & 0.727 \\
0.825 & 1.000 & 0.754 & 0.912 \\
0.813 & 0.780 & 0.929 & 1.000 \\
1.000 & 0.730 & 0.378 & 0.514 \\
1.000 & 0.486 & 0.895 & 0.850 \\
0.857 & 1.000 & 0.367 & 0.612
\end{array}\right]
$$

3) Use model (SOP1) and (SOP2) to get ideal point $\bar{z}$ and minus ideal point $\underline{z}$, $\bar{z}=(0.9567,0.8168,0.8169,0.8174), \underline{z}=(0.9105,0.6883,0.6674,0.7003)$

4) Use equation (2) to calculate $a=1.4906, b=1.7083$;

5) Use model (SOP3) to get the following single-objective decision model:

Target function:

$$
\begin{aligned}
\max s(\omega) & =\frac{a f(\omega)}{a f(\omega)+b g(\omega)} \\
& =\frac{4.476 \omega_{1}+4.440 \omega_{2}+4.475 \omega_{3}+3.414 \omega_{4}+4.158 \omega_{5}+3.646 \omega_{6}}{8.939 \omega_{1}+8.848 \omega_{2}+8.911 \omega_{3}+6.873 \omega_{4}+8.321 \omega_{5}+7.304 \omega_{6}}
\end{aligned}
$$

Restraints:

$$
\begin{aligned}
& 0.2 \leq \omega_{1} \leq 0.4,0.1 \leq \omega_{2} \leq 0.35,0.1 \leq \omega_{3} \leq 0.3,0.15 \leq \omega_{4} \leq 0.4, \\
& 0.15 \leq \omega_{5} \leq 0.4,0.05 \leq \omega_{6} \leq 0.15, \omega_{1}+\omega_{2}+\omega_{3}+\omega_{4}+\omega_{5}+\omega_{6}=1
\end{aligned}
$$

Ideal solution is $\omega^{*}=(0.2,0.1,0.1,0.15,0.3,0.15)$. Close degree is $s\left(\omega^{*}\right)=0.4999$. The relevant comprehensive attribute value vector is $z\left(\omega^{*}\right)=(0.9432,0.7397,0.7449,0.7605)$. So schemes ranks are $x_{1}>x_{4}>x_{3}>x_{2}$. The optimal scheme is $x_{1}$.

\section{Conclusion}

Decision-making model based on the scheme close degree can determine what is the optimal plan in the lack of 
weight information and thus provides scientific basis for decision makers to draw up electronic business investment programmes under uncertain conditions. From the example analysis, this model not only determines what is the optimal plan but also ascertains weights for each attribute influencing decisions. Decision makers can know the importance of each attribute according to the size of their weights and give greater attention to big-weight attributes based on the actual situation, so they can adopt pointed countermeasures in order to get more benefit.

\section{References}

[1] Liu, D.F. (2010) Two Decision-Making Methods on Solving Multi-Target Problems with Incomplete Information. Systems Engineering and Electronics, No. 6, 70-74.

[2] Liu, S.L. and Qiu, W.H. (2012) Multi-Attribute Basic Decision-Making Theory Research. Systems Engineering-Theory \& Practice, No. 8, 50-55.

[3] Wang, W.P. (2014) Multi-Objective Optimization Method Research with Incomplete Information. Journal of Systems Engineering, No. 4, 32-36.

[4] Xu, N.R. and Zhong, W.J. (2013) Scientific Decision Theory and Method. Southeast University Press, Shanghai, No. 5, 40-43.

[5] Xu, Z.S. (2011) The Ranking Method Research of Fuzzy Comprehensive Evaluation. Research Information Ltd. Press, Beijing, No. 9, 53-56.

\section{Submit or recommend next manuscript to SCIRP and we will provide best service for you:}

Accepting pre-submission inquiries through Email, Facebook, Linkedin, Twitter, etc

A wide selection of journals (inclusive of 9 subjects, more than 200 journals)

Providing a 24-hour high-quality service

User-friendly online submission system

Fair and swift peer-review system

Efficient typesetting and proofreading procedure

Display of the result of downloads and visits, as well as the number of cited articles

Maximum dissemination of your research work

Submit your manuscript at: http://papersubmission.scirp.org/ 